\title{
Outcome of severe lactic acidosis associated with metformin accumulation
}

Sigrun Friesecke ${ }^{1 *}$, Peter Abel ${ }^{1}$, Markus Roser ${ }^{2}$, Stephan B Felix ${ }^{1}$, Soeren Runge ${ }^{3}$

\begin{abstract}
Introduction: Metformin associated lactic acidosis (MALA) may complicate metformin therapy, particularly if metformin accumulates due to renal dysfunction. Profound lactic acidosis (LA) generally predicts poor outcome. We aimed to determine if MALA differs in outcome from LA of other origin (LAOO).

Methods: We conducted a retrospective analysis of all patients admitted with LA to our medical ICU of a tertiary referral center during a 5-year period. MALA patients and LAOO patients were compared with respect to parameters of acid-base balance, serum creatinine, hospital outcome, Simplified Acute Physiology Score II (SAPS II) and Sequential Organ Failure Assessment (SOFA) score, using Pearson's Chi-square or the Mann-Whitney U-test.

Results: Of 197 patients admitted with LA, 10 had been diagnosed with MALA. With MALA, median arterial blood $\mathrm{pH}$ was significantly lower (6.78 [range 6.5 to 6.94]) and serum lactate significantly higher (18.7 $\pm 5.3 \mathrm{mmol} / \mathrm{L})$ than with LAOO (pH 7.20 [range 6.46 to 7.35], mean serum lactate $11.2 \pm 6.1 \mathrm{mmol} / \mathrm{L})$. Overall mortality, however, was comparable (MALA 50\%, LAOO 74\%). Furthermore, survival of patients with arterial blood pH $<7.00(N=41)$ was significantly better $(50 \%$ vs. $0 \%)$ if MALA $(N=10)$ was the underlying condition compared to LAOO $(N=31)$.
\end{abstract}

Conclusions: Compared to similarly severe lactic acidosis of other origin, the prognosis of MALA is significantly better. MALA should be considered in metformin-treated patients presenting with lactic acidosis.

\section{Introduction}

Metformin is recommended as the treatment of choice in patients with type 2 diabetes mellitus because it decreases cardiovascular morbidity and mortality $[1,2]$. Nevertheless, metformin-associated lactic acidosis (MALA) is a rare but potentially life-threatening complication with a mortality rate of $30 \%$ to $50 \%[3,4]$. The biochemical mechanism of MALA is still not fully understood. Presumably, accumulated metformin suppresses biological oxidation and the enzymes of the citric acid cycle [3,5-7]. Moreover, recent studies have reported that metformin action may be mediated by the regulation of gene expression [8-10]. The pathogenesis of MALA is controversial. MALA is assumed to be triggered by an acute primary tissue hypoxia as in septic shock or cardiovascular failure in most cases $[1,3,11,12]$. Some authors dispute whether metformin may contribute to lactic acidosis (LA) at all $[12,13]$. However, cases

\footnotetext{
* Correspondence: sigrun.friesecke@uni-greifswald.de

'Department of Cardiology, Pneumology and Intensive Care Medicine, Ernst Moritz Arndt University, 17475 Greifswald, Germany

Full list of author information is available at the end of the article
}

of MALA solely following drug accumulation have been reported [5,14-16]. Furthermore, data from a US poison center give some evidence that a large single ingestion can lead to LA [17]. Remarkably, severe MALA may have an unexpectedly favorable outcome $[4,14,15]$. Therefore, the aim of this study was to compare the outcomes of MALA and LA of other origin (LAOO).

\section{Materials and methods}

This retrospective analysis was approved by the institutional ethics committee at Ernst Moritz Arndt University of Greifswald. The necessity of patient consent was waived. All patients admitted to the medical intensive care unit of our tertiary referral center during a 5 -year period (2004 to 2008) were screened for LA (that is, lactate of greater than $5 \mathrm{mmol} / \mathrm{L}$ and $\mathrm{pH}$ of not more than 7.35 [11]) on admission by using the laboratory database.

Clinical characteristics, admission laboratory results, metformin plasma levels, and hospital survival of all LA patients were extracted from patient files. To compare severity of disease, Simplified Acute Physiology Score II (SAPS II) [18,19] and Sequential Organ Failure
C Biomed Central

() 2010 Friesecke et al.; licensee BioMed Central Ltd. This is an open access article distributed under the terms of the Creative Commons Attribution License (http://creativecommons.org/licenses/by/2.0), which permits unrestricted use, distribution, and reproduction in any medium, provided the original work is properly cited. 
Assessment (SOFA) score $[20,21]$ were extracted from the ward database. According to discharge diagnoses, patients were categorized under the following entities of LA: MALA, post-cardiopulmonary resuscitation, septic shock, cardiogenic shock, acute mesenteric ischemia, hemorrhagic shock, or other. The diagnosis of MALA was confirmed retrospectively by critical review of patient charts, which included data on medical history, clinical presentation, highly elevated plasma levels of metformin, and absence of other common causes of LA. None of the patients had evidence of hepatic failure. All MALA patients had an electrocardiogram and a bedside echocardiogram to rule out myocardial infarction and relevant cardiac dysfunction. None had evidence of a septic focus in chest $\mathrm{x}$-ray, abdominal or thoracic ultrasound, blood cultures, urinary dipstick (if not anuric), or computed tomography (if indicated). MALA patients were compared with all LAOO patients and with the severely acidotic subgroup $(\mathrm{pH}<7.0)$ of LAOO patients with respect to parameters of acid-base balance, serum creatinine, SAPS II, and hospital outcome by using the Pearson chi-square test or the Mann-Whitney $U$ test.

\section{Results}

During the study period, 197 patients were admitted with LA. MALA was diagnosed in 10 patients, none had deliberately overdosed (daily metformin dose of 1,900 $\pm 356 \mathrm{mg}$ ), but all had severe renal failure (median admission serum creatinine of $776 \mu \mathrm{mol} / \mathrm{L}$, range of 347 to 1,502$)$ that had not been noticed before. In 6 patients, previous diarrhea or vomiting or both were reported; in the other 4 , no cause for acute renal failure could be identified, but 3 of them had pre-existing chronic renal insufficiency. Metformin plasma levels were highly toxic in all MALA patients (median of $55 \mathrm{mg} / \mathrm{L}$, range of 31 to 85 , therapeutic range of 0.2 to 1.3). All MALA patients were in circulatory shock and were treated with vasopressors. Nevertheless, in 8 of them, circulatory failure deteriorated up to cardiocirculatory arrest, which was reversible with cardiopulmonary resuscitation. All MALA patients were mechanically ventilated and immediately treated with continuous veno-venous hemodialysis or hemofiltration. In MALA, LA and renal dysfunction were significantly more severe, other organ dysfunctions were similar, but mortality was not significantly higher compared with all LAOO patients and with each of the causal entities of LAOO (Table 1).

All MALA patients and 31 of the LAOO patients had very severe acidosis $(\mathrm{pH}<7.0)$. In this subgroup, acidbase imbalance in MALA was still slightly more profound than in LAOO, severity of disease and non-renal organ dysfunction (SAPS II and SOFA score) were comparable, but outcome was significantly better (50\% survivors in MALA versus $0 \%$ in LAOO) (Table 2).

There was no difference within the MALA group between survivors and non-survivors in regard to serum metformin level, the degree of LA, or organ dysfunction

Table 1 Comparison of patients with metformin-associated lactic acidosis with patients with lactic acidosis of other origin

\begin{tabular}{|c|c|c|c|c|c|c|c|c|c|}
\hline & $\begin{array}{c}\text { All } \\
\text { patients } \\
(n=197)\end{array}$ & $\begin{array}{c}\text { MALA } \\
(n=10)\end{array}$ & $\begin{array}{c}\text { LAOO } \\
(n=187)\end{array}$ & $\begin{array}{c}\text { Post- } \\
\text { cardiac } \\
\text { arrest } \\
(n=72)\end{array}$ & $\begin{array}{c}\text { Septic } \\
\text { shock } \\
(n=42)\end{array}$ & $\begin{array}{c}\text { Cardiogenic } \\
\text { shock } \\
(n=39)\end{array}$ & $\begin{array}{l}\text { Mesenteric } \\
\text { ischemia } \\
(n=8)\end{array}$ & $\begin{array}{c}\text { Hemorrhagic } \\
\text { shock } \\
(n=13)\end{array}$ & $\begin{array}{l}\text { Other } \\
\text { causes } \\
(n=13)\end{array}$ \\
\hline Age, years & $67 \pm 13$ & $66 \pm 9$ & $67 \pm 13$ & $65 \pm 13$ & $68 \pm 12$ & $73 \pm 11$ & $72 \pm 9$ & $64 \pm 15$ & $56 \pm 14$ \\
\hline Male gender & $121(61 \%)$ & $4(40 \%)$ & 117 (63\%) & 45 (62\%) & $24(57 \%)$ & $26(67 \%)$ & $6(75 \%)$ & 7 (54\%) & $9(69 \%)$ \\
\hline SAPS ॥ & $74 \pm 20$ & $88 \pm 23$ & $73 \pm 19^{a}$ & $81 \pm 16$ & $71 \pm 19^{a}$ & $75 \pm 18$ & $73 \pm 25$ & $54 \pm 15^{b}$ & $54 \pm 14^{b}$ \\
\hline SOFA score & $12.5 \pm 3.6$ & $14.3 \pm 1.4$ & $12.4 \pm 3.7$ & $12.9 \pm 2.9$ & $12.1 \pm 4.5$ & $11.8 \pm 2.8^{b}$ & $14.4 \pm 4.4$ & $13.4 \pm 4.6$ & $9.6 \pm 4.2^{b}$ \\
\hline Respiratory & $2.5 \pm 1.0$ & $2.7 \pm 0.9$ & $2.5 \pm 1.0$ & $2.7 \pm 0.9$ & $2.1 \pm 1.3$ & $2.4 \pm 0.6$ & $2.6 \pm 1.1$ & $2.3 \pm 1.5$ & $2.2 \pm 1.4$ \\
\hline Renal & $2.4 \pm 1.2$ & $4.0 \pm 0.0$ & $2.3 \pm 1.2^{b}$ & $2.1 \pm 1.2^{b}$ & $2.5 \pm 1.2^{b}$ & $2.5 \pm 1.1^{b}$ & $2.8 \pm 0.8^{a}$ & $2.1 \pm 1.5^{b}$ & $1.9 \pm 1.3^{b}$ \\
\hline Hepatic & $0.7 \pm 1.0$ & $0.3 \pm 0.7$ & $0.7 \pm 1.0$ & $0.3 \pm 0.6$ & $1.3 \pm 1.2^{\mathrm{a}}$ & $0.6 \pm 0.8$ & $0.6 \pm 0.9$ & $1.8 \pm 1.7$ & $0.9 \pm 0.9$ \\
\hline Cardiovascular & $3.3 \pm 1.4$ & $4.0 \pm 0.0$ & $3.3 \pm 1.5$ & $3.5 \pm 1.3$ & $3.2 \pm 1.5$ & $3.4 \pm 1.5$ & $4.0 \pm 0.0$ & $2.9 \pm 1.8$ & $2.1 \pm 2.0^{a}$ \\
\hline Hematologic & $0.9 \pm 1.2$ & $0.5 \pm 0.8$ & $0.9 \pm 1.2$ & $0.6 \pm 0.9$ & $1.3 \pm 1.4$ & $0.3 \pm 0.7$ & $2.2 \pm 1.6$ & $2.6 \pm 1.1$ & $0.9 \pm 1.2$ \\
\hline Neurologic & $2.7 \pm 1.4$ & $2.8 \pm 1.5$ & $2.7 \pm 1.4$ & $3.7 \pm 0.6^{a}$ & $1.7 \pm 1.3^{\mathrm{a}}$ & $2.8 \pm 1.2$ & $2.2 \pm 1.3$ & $1.8 \pm 1.4^{b}$ & $1.6 \pm 1.2$ \\
\hline Lactate, mmol/L & $11.6 \pm 6.2$ & $18.7 \pm 5.3$ & $11.2 \pm 6.1^{b}$ & $12.8 \pm 6.1^{b}$ & $8.7 \pm 4.5^{b}$ & $10.9 \pm 5.2^{b}$ & $8.6 \pm 3.3^{b}$ & $13.5 \pm 9.5^{b}$ & $10.8 \pm 7.1^{b}$ \\
\hline $\mathrm{pH}$ & $7.13 \pm 0.19$ & $\begin{array}{c}6.75 \pm \\
0.13\end{array}$ & $\begin{array}{c}7.15 \pm \\
0.17^{\mathrm{b}}\end{array}$ & $7.07 \pm 0.19^{b}$ & $7.23 \pm 0.09^{b}$ & $7.18 \pm 0.14^{b}$ & $7.27 \pm 0.04^{b}$ & $7.26 \pm 0.07^{b}$ & $7.14 \pm 0.18^{b}$ \\
\hline $\begin{array}{l}\text { Bicarbonate, } \\
\mathrm{mmol} / \mathrm{L}\end{array}$ & $14.6 \pm 5.9$ & $4.4 \pm 2.4$ & $15.2 \pm 5.6^{b}$ & $14.5 \pm 5.6^{b}$ & $16.6 \pm 5.8^{b}$ & $14.9 \pm 4.0^{b}$ & $16.2 \pm 1.8^{\mathrm{b}}$ & $15.8 \pm 5.7^{b}$ & $14.1 \pm 8.8^{b}$ \\
\hline Creatinine, $\mu \mathrm{mol} / \mathrm{L}$ & $307 \pm 265$ & $796 \pm 324$ & $227 \pm 141^{b}$ & $169 \pm 128^{b}$ & $318 \pm 181^{b}$ & $182 \pm 48^{b}$ & $299 \pm 125^{a}$ & $303 \pm 122^{a}$ & $214 \pm 57^{b}$ \\
\hline Survival & $52(26 \%)$ & $5(50 \%)$ & $48(26 \%)$ & $19(26 \%)$ & $9(21 \%)$ & $9(23 \%)$ & 0 & $5(38 \%)$ & $6(46 \%)$ \\
\hline
\end{tabular}

Values are presented as mean \pm standard deviation or as number (percentage). Comparison with metformin-associated lactic acidosis (MALA): ${ }^{\text {a }} P<0.05$, ${ }^{\text {b }} P<$ 0.01. Simplified Acute Physiology Score II (SAPS II) and Sequential Organ Failure Assessment (SOFA) score were measured on admission. Other causes of lactic acidosis were respiratory exhaustion (3), alcoholic lactic acidosis (3), acute liver failure (2), status epilepticus (2), anaphylactic shock, hypovolemic shock, and disseminated intravascular coagulation in acute myeloid leukemia. LAOO, lactic acidosis of other origin. 
Table 2 Comparison of metformin-associated lactic acidosis and very severe lactic acidosis of other origin (pH $<7.0)$

\begin{tabular}{|c|c|c|c|}
\hline & All patients with $\mathrm{pH}<7.0(n=41)$ & MALA $(n=10)$ & LAOO $(n=31)$ \\
\hline Age, years & $64 \pm 13$ & $66 \pm 9$ & $64 \pm 14$ \\
\hline Male gender & $19(46 \%)$ & $4(40 \%)$ & $15(48 \%)$ \\
\hline SAPS ॥ & $84 \pm 18$ & $88 \pm 23$ & $83 \pm 16$ \\
\hline SOFA score & $14.0 \pm 2.9$ & $14.3 \pm 1.4$ & $13.8 \pm 3.4$ \\
\hline Respiratory & $2.7 \pm 1.0$ & $2.7 \pm 0.9$ & $2.8 \pm 1.0$ \\
\hline Renal & $3.0 \pm 1.1$ & $4.0 \pm 0.0$ & $2.6 \pm 1.1^{\mathrm{a}}$ \\
\hline Hepatic & $0.5 \pm 0.8$ & $0.3 \pm 0.7$ & $0.6 \pm 0.9$ \\
\hline Cardiovascular & $3.6 \pm 1.2$ & $4.0 \pm 0.0$ & $3.4 \pm 1.4$ \\
\hline Hematologic & $0.8 \pm 1.1$ & $0.5 \pm 0.8$ & $0.9 \pm 1.2$ \\
\hline Neurologic & $3.3 \pm 1.2$ & $2.8 \pm 1.5$ & $3.5 \pm 1.1$ \\
\hline Lactate, $\mathrm{mmol} / \mathrm{L}$ & $18.1 \pm 6.5$ & $18.7 \pm 5.3$ & $17.9 \pm 6.9$ \\
\hline $\mathrm{pH}$ & $6.83 \pm 0.12$ & $6.75 \pm 0.13$ & $6.86 \pm 0.11^{\mathrm{a}}$ \\
\hline Bicarbonate, $\mathrm{mmol} / \mathrm{L}$ & $9.0 \pm 4.8$ & $4.4 \pm 2.4$ & $10.5 \pm 4.5^{\mathrm{a}}$ \\
\hline Creatinine, $\mu \mathrm{mol} / \mathrm{L}$ & $529 \pm 392$ & $796 \pm 324$ & $195 \pm 91^{\mathrm{a}}$ \\
\hline Survival & $4(10 \%)$ & $5(50 \%)$ & $0(0 \%)^{\mathrm{a}}$ \\
\hline
\end{tabular}

Values are presented as mean \pm standard deviation or as number (percentage). Comparison with metformin-associated lactic acidosis (MALA): ${ }^{2} P<0.01$. LAOO, lactic acidosis of other origin; SAPS II, Simplified Acute Physiology Score II; SOFA, Sequential Organ Failure Assessment.

(Table 3). MALA patients who did not survive died from refractory circulatory failure after a median of 27 hours (range of 3 to 41 hours) from intensive care unit admission.

\section{Discussion}

In 10 out of 197 patients in our study, LA on admission was found to be associated with metformin accumulation. MALA patients had the most severe acid-base imbalance but did not have a worse outcome. Mortality rates in our study are in accordance with those published by other authors. For MALA, a mortality of $30 \%$ to $50 \%$ has been reported $[3,4,22]$; for LA in general, a mortality of up to $83 \%$ has been reported [23,24].
Mortality is generally correlated with lactate levels $[24,25]$. For MALA, data are less clear. After a retrospective analysis in 1999, Lalau and Race [25,26] reasoned that neither lactate nor metformin levels were of prognostic value in MALA since, in their study, the lactate and metformin levels of survivors were, respectively, similar to and higher than those of patients who died. The authors suppose that the underlying condition, and not metformin accumulation, determined outcome. In contrast, Dell'Aglio and colleagues [27] reported a correlation between $\mathrm{pH}$ nadir, metformin level, and outcome.

Recently, observations in two series of MALA were published [4,22]. Peters and colleagues [22] reported 30 patients who were generally less sick than ours (less

Table 3 Comparison of survived versus deceased patients with metformin-associated lactic acidosis

\begin{tabular}{lccc}
\hline & All patients with MALA $(\boldsymbol{n}=\mathbf{1 0})$ & Survived $(\boldsymbol{n}=\mathbf{5})$ & Deceased $(\boldsymbol{n}=\mathbf{5})$ \\
\hline Age, years & $66 \pm 9$ & $64 \pm 5$ & $69 \pm 11$ \\
Male gender & $4(40 \%)$ & $3(60 \%)$ & $1(20 \%)$ \\
SAPS II & $88 \pm 23$ & $73 \pm 25$ & $103 \pm 7$ \\
SOFA score & $14.3 \pm 1.4$ & $13.8 \pm 1.5$ & $14.8 \pm 1.3$ \\
$\quad 2.7 \pm 0.9$ & $2.4 \pm 1.1$ & $3.0 \pm 0.7$ \\
$\quad$ Respiratory & $4.0 \pm 0.0$ & $4.0 \pm 0.0$ & $4.0 \pm 0.0$ \\
$\quad$ Renal & $0.3 \pm 0.7$ & $0.4 \pm 0.9$ & $0.2 \pm 0.4$ \\
$\quad$ Hepatic & $4.0 \pm 0.0$ & $4.0 \pm 0.0$ & $4.0 \pm 0.0$ \\
$\quad$ Cardiovascular & $0.5 \pm 0.8$ & $0.4 \pm 0.9$ & $0.6 \pm 0.9$ \\
$\quad$ Hematologic & $2.8 \pm 1.5$ & $2.6 \pm 1.3$ & $3.0 \pm 1.7$ \\
Lactate, mmol/L & $18.7 \pm 5.3$ & $17.7 \pm 5.3$ & $19.8 \pm 5.7$ \\
pH & $6.75 \pm 0.13$ & $6.72 \pm 0.17$ & $6.77 \pm 0.07$ \\
Prothrombin activity, \% & $69.1 \pm 27.7^{\mathrm{a}}$ & $78.0 \pm 24.6$ & $58.0 \pm 30.7^{\mathrm{a}}$ \\
Serum metformin, mg/L & $55 \pm 13$ & $52 \pm 7$ & $58 \pm 19$ \\
\hline
\end{tabular}

Values other than 'Male gender', which is presented as number (percentage), are presented as mean \pm standard deviation. ${ }^{\mathrm{a} O n e}$ patient was omitted with $11 \%$ prothrombin activity due to cumarin therapy. MALA, metformin-associated lactic acidosis; SAPS II, Simplified Acute Physiology Score II; SOFA, Sequential Organ Failure Assessment. 
acidotic, less frequently in shock, lower SAPS II, and less frequently ventilated) and in whom mortality was $30 \%$ compared with our $50 \%$. Seidowsky and colleagues [4] reported 42 patients, 29 of whom had incidental metformin accumulation. In these 29 patients, severity of acidosis (mean pH of 6.9) and mortality (48.3\%) were comparable to those of our MALA patients [4]. In both series, decreased prothrombin activity on admission was associated with mortality $[4,22]$. In our small number of cases, we could not reproduce this association.

Compared with our LAOO subgroup with similarly severe acid-base imbalance $(\mathrm{pH}<7.0)$, the outcome of MALA patients was significantly better. Lalau and Race [28] reported decreased mortality for patients who had a $\mathrm{pH}$ of less than 7 and who had been treated with metformin ( $81 \%$ versus 99\%) and this is consistent with our results.

We suppose that the different outcomes of MALA and LAOO may have been because, unlike most cases of LAOO, LA in MALA is not due primarily to shock or ischemia and because our patients had no underlying condition serious enough to cause severe LA in the absence of metformin accumulation. Furthermore, it has been hypothesized that metformin, possibly through its beneficial effects on vasomotility, might even be protective in shock $[26,29]$.

MALA may develop without an underlying disease or may aggravate LAOO, or metformin may accumulate just coincidentally with LA $[3,12]$. In any given patient, it will be difficult to establish the causative role of metformin accumulation in the development of LA [4]. Furthermore, the role of metformin in the development of LA is controversial; some authors deny any causal involvement $[12,13]$ altogether, and others believe that metformin actually induces LA in certain cases [30]. Clinical data in general and our retrospective observation in particular are not suitable to decide this issue definitely, but our results and those of other authors point to the latter position $[4,5,14-17,22,27]$. In our MALA patients, no other cause for LA was identified, and highly elevated metformin plasma levels were measured. In these patients, previously unnoticed deterioration of renal function explained why metformin had accumulated despite having been taken in usual doses. The much greater extent of renal dysfunction in MALA compared with similarly severe LAOO suggests that renal failure not only complicated MALA but also indeed contributed to the pathogenesis. Progressive renal impairment has been recognized as a risk factor for MALA $[14,15,30]$ and cannot be held responsible for LA as a single condition in the absence of metformin [31].

MALA may be more common in severely acidotic patients: $24 \%$ of our patients with $\mathrm{pH}$ of less than 7 were diagnosed with MALA. Therefore, given the unexpectedly favorable prognosis, it appears important to consider MALA and look into the possibility of metformin therapy when a patient is admitted with very severe LA. It may be safely assumed that, in such severely ill patients, only prompt and rigorous therapy allows this favorable prognosis [14]. Anecdotal evidence suggests that high-volume renal replacement therapy may be beneficial in severe MALA $[5,32,33]$.

\section{Limitations}

Our study included a limited number of patients. The incidence of MALA is low, and therefore recruitment of patients is demanding. In this study, we included 10 patients seen in one institution during a 5-year period. A second limitation is the retrospective design. A bias in patient selection cannot be excluded. As metformin levels were usually not determined in cases in which alternative causes of LA had been identified, coincident metformin accumulation may have been missed. To our knowledge, though, this is the first direct comparison between MALA and LAOO.

\section{Conclusions}

The outcome of very severe MALA $(\mathrm{pH}<7)$ is much better than might be expected from the comparison with similarly severe LAOO. To ensure adequate therapy, it appears important to consider an association with metformin and look into the possibility of metformin medication in all cases of very severe LA.

\section{Key messages}

- Given the same profound level of acidosis, prognosis of metformin-associated lactic acidosis (MALA) is significantly better than that of lactic acidosis of other origin.

- It is important to consider MALA in any metformin-treated patient and to start therapy promptly.

\section{Abbreviations}

LA: lactic acidosis; LAOO: lactic acidosis of other origin; MALA: metforminassociated lactic acidosis; SAPS II: Simplified Acute Physiology Score II; SOFA: Sequential Organ Failure Assessment.

\section{Author details}

'Department of Cardiology, Pneumology and Intensive Care Medicine, Ernst Moritz Arndt University, 17475 Greifswald, Germany. ${ }^{2}$ Department of Clinical Chemistry and Laboratory Medicine, Ernst Moritz Arndt University, 17475 Greifswald, Germany. ${ }^{3}$ Department of Gastroenterology, Nephrology,

Endocrinology, Nutrition, Ernst Moritz Arndt University, 17475 Greifswald, Germany.

\section{Authors' contributions}

$S$ Friesecke conceived of the study and helped to draft the manuscript. PA participated in the design of the study and performed the statistical analysis. MR carried out data collection and data analysis. S Felix participated in the design and coordination of the study. SR participated in the design of the study and drafted the manuscript. All authors read and approved the final manuscript. 


\section{Competing interests}

The authors declare that they have no competing interests.

Received: 7 May 2010 Revised: 14 July 2010

Accepted: 20 December 2010 Published: 20 December 2010

\section{References}

1. Jones GC, Macklin JP, Alexander WD: Contraindications to the use of metformin. BMJ 2003, 326:4-5.

2. Effect of intensive blood-glucose control with metformin on complications in overweight patients with type 2 diabetes (UKPDS 34). UK Prospective Diabetes Study (UKPDS) Group. Lancet 1998, 352:854-865.

3. Kirpichnikov D, McFarlane SI, Sowers JR: Metformin: an update. Ann Intern Med 2002, 137:25-33.

4. Seidowsky A, Nseir S, Houdret N, Fourrier F: Metformin-associated lactic acidosis: a prognostic and therapeutic study. Crit Care Med 2009, 37:2191-2196.

5. Chang $C T$, Chen $Y C$, Fang JT, Huang CC: Metformin-associated lactic acidosis: case reports and literature review. J Nephrol 2002, 15:398-402.

6. Leverve XM, Guigas B, Detaille D, Batandier C, Koceir EA, Chauvin C, Fontaine $E$, Wiernsperger NF: Mitochondrial metabolism and type-2 diabetes: a specific target of metformin. Diabetes Metab 2003, 29:6588-94.

7. Dykens JA, Jamieson J, Marroquin L, Nadanaciva S, Billis PA, Will Y: Biguanide-induced mitochondrial dysfunction yields increased lactate production and cytotoxicity of aerobically-poised HepG2 cells and human hepatocytes in vitro. Toxicol Appl Pharmacol 2008, 233:203-210.

8. Caton PW, Nayuni NK, Kieswich J, Khan NQ, Yaqoob MM, Corder R: Metformin suppresses hepatic gluconeogenesis through induction of SIRT1 and GCN5. J Endocrinol 2010, 205:97-106.

9. Fujita Y, Hosokawa M, Fujimoto S, Mukai E, Abudukadier A, Obara A, Ogura M, Nakamura Y, Toyoda K, Nagashima K, Seino Y, Inagaki N: Metformin suppresses hepatic gluconeogenesis and lowers fasting blood glucose levels through reactive nitrogen species in mice. Diabetologia 2010, 53:1472-1481.

10. Kim YD, Park KG, Lee YS, Park YY, Kim DK, Nedumaran B, Jang WG, Cho WJ, Ha J, Lee IK, Lee CH, Choi HS: Metformin inhibits hepatic gluconeogenesis through AMP-activated protein kinase-dependent regulation of the orphan nuclear receptor SHP. Diabetes 2008, 57:306-314.

11. Salpeter SR, Greyber E, Pasternak GA, Salpeter EE: Risk of fatal and nonfatal lactic acidosis with metformin use in type 2 diabetes mellitus: systematic review and meta-analysis. Arch Intern Med 2003, 163:2594-2602.

12. Misbin Rl: The phantom of lactic acidosis due to metformin in patients with diabetes. Diabetes Care 2004, 27:1791-1793.

13. Holstein A, Stumvoll M: Contraindications can damage your health-is metformin a case in point? Diabetologia 2005, 48:2454-2459.

14. Fitzgerald E, Mathieu S, Ball A: Metformin associated lactic acidosis. BMJ 2009, 339:b3660

15. Runge S, Mayerle J, Warnke C, Robinson D, Roser M, Felix SB, Friesecke S: Metformin-associated lactic acidosis in patients with renal impairment solely due to drug accumulation? Diabetes Obes Metab 2008, 10:91-93.

16. Velzen A, Riel A, Vries I, Meulenbelt J: The dangers of metformin: fatal lactic acidosis with therapeutic use due to renal failure. Toxicol Lett 2008, 180:S142-S143.

17. Wills BK, Bryant SM, Buckley P, Seo B: Can acute overdose of metformin lead to lactic acidosis? Am J Emerg Med 2010, 28:857-861.

18. Le Gall JR, Lemeshow S, Saulnier F: A new Simplified Acute Physiology Score (SAPS II) based on a European/North American multicenter study. JAMA 1993, 270:2957-2963.

19. Le Gall JR, Neumann A, Hemery F, Bleriot JP, Fulgencio JP, Garrigues B, Gouzes C, Lepage E, Moine P, Villers D: Mortality prediction using SAPS II: an update for French intensive care units. Crit Care 2005, 9:R645-652.

20. Vincent JL, de Mendonca A, Cantraine F, Moreno R, Takala J, Suter PM, Sprung CL, Colardyn F, Blecher S: Use of the SOFA score to assess the incidence of organ dysfunction/failure in intensive care units: results of a multicenter, prospective study. Working group on "sepsis-related problems" of the European Society of Intensive Care Medicine. Crit Care Med 1998, 26:1793-1800.

21. Vincent JL, Moreno R, Takala J, Willatts S, De Mendonca A, Bruining H, Reinhart CK, Suter PM, Thijs LG: The SOFA (Sepsis-related Organ Failure Assessment) score to describe organ dysfunction/failure. On behalf of the Working Group on Sepsis-Related Problems of the European Society of Intensive Care Medicine. Intensive Care Med 1996, 22:707-710.

22. Peters N, Jay N, Barraud D, Cravoisy A, Nace L, Bollaert PE, Gibot S: Metformin-associated lactic acidosis in an intensive care unit. Crit Care 2008, 12:R149

23. Stacpoole PW, Wright EC, Baumgartner TG, Bersin RM, Buchalter S, Curry SH Duncan C, Harman EM, Henderson GN, Jenkinson S, et al: Natural history and course of acquired lactic acidosis in adults. DCA-Lactic Acidosis Study Group. Am J Med 1994, 97:47-54.

24. Smith I, Kumar P, Molloy S, Rhodes A, Newman PJ, Grounds RM, Bennett ED: Base excess and lactate as prognostic indicators for patients admitted to intensive care. Intensive Care Med 2001, 27:74-83.

25. Lalau JD, Race JM: Lactic acidosis in metformin-treated patients. Prognostic value of arterial lactate levels and plasma metformin concentrations. Drug Saf 1999, 20:377-384.

26. Lalau JD, Race JM: Lactic acidosis in metformin therapy. Drugs 1999, 58(Suppl 1):55-60, discussion 75-82.

27. Dell'Aglio DM, Perino LJ, Kazzi Z, Abramson J, Schwartz MD, Morgan BW: Acute metformin overdose: examining serum $\mathrm{pH}$, lactate level, and metformin concentrations in survivors versus nonsurvivors: a systematic review of the literature. Ann Emerg Med 2009, 54:818-823.

28. Lalau JD, Race JM: Metformin and lactic acidosis in diabetic humans. Diabetes Obes Metab 2000, 2:131-137.

29. Gras V, Bouffandeau B, Montravers PH, Lalau JD: Effect of metformin on survival rate in experimental sepsis. Diabetes Metab 2006, 32:147-150.

30. Fantus IG: Metformin's contraindications: needed for now. CMAJ 2005, 173:505-507.

31. De Backer D: Lactic acidosis. Intensive Care Med 2003, 29:699-702.

32. Panzer U, Kluge S, Kreymann G, Wolf G: Combination of intermittent haemodialysis and high-volume continuous haemofiltration for the treatment of severe metformin-induced lactic acidosis. Nephrol Dial Transplant 2004, 19:2157-2158.

33. Friesecke $S$, Abel P, Kraft M, Gerner A, Runge S: Combined renal replacement therapy for severe metformin-induced lactic acidosis. Nephrol Dial Transplant 2006, 21:2038-2039.

\section{doi:10.1186/cc9376}

Cite this article as: Friesecke et al:: Outcome of severe lactic acidosis associated with metformin accumulation. Critical Care 2010 14:R226.

\section{Submit your next manuscript to BioMed Central and take full advantage of:}

- Convenient online submission

- Thorough peer review

- No space constraints or color figure charges

- Immediate publication on acceptance

- Inclusion in PubMed, CAS, Scopus and Google Scholar

- Research which is freely available for redistribution

Submit your manuscript at www.biomedcentral.com/submit
C Biomed Central 